\title{
Modelo de mobilidade veicular urbano baseado em traços reais de mobilidade
}

\author{
Régis Thiago Feyh ${ }^{1}$ and Marco Aurélio Spohn ${ }^{2}$ \\ 1,2 Universidade Federal da Fronteira Sul , Curso de Ciência da Computação , Chapecó/SC \\ *registhiagofeyh@gmail.com; ${ }^{\dagger}$ marco.spohn@uffs.edu.br
}

Submetido: 16/10/2017. Revisado: 23/03/2018. Aceito: 15/04/2018.

\begin{abstract}
Resumo
Este artigo apresenta e valida um modelo de mobilidade veicular urbano resultante da análise de traços reais de mobilidade de táxis da cidade de Roma (Itália). O modelo de mobilidade é aplicado em um simulador de tráfego, possibilitando-se gerar traços sintéticos de mobilidade para simuladores de redes. A principal vantagem de se gerar traços sintéticos é que, além de manter aspectos do padrão de mobilidade real, permite-se um maior controle das variáveis do ambiente de simulação. Apesar do modelo proposto não conseguir capturar todos os aspectos reais da mobilidade dos táxis, mostrou-se efetivo em reproduzir características observadas como relevantes na movimentação veicular urbana.
\end{abstract}

Palavras-Chave: Modelo de mobilidade; redes veiculares; simulação de tráfego urbano; traços de mobilidade.

\section{Abstract}

This article presents, and validates, a model for urban vehicular mobility based on the analysis of taxi movement traces from the city of Rome, Italy. The mobility model is applied in a traffic simulator, making it possible to generate synthetic mobility traces for network simulators. The main advantage of generating synthetic traces is that, while keeping real mobility patterns, it is possible to better control the simulation variables. Even though the proposed model does not capture all the real aspects of taxi mobility, it has been effective in reproducing characteristics observed as relevant in urban vehicular mobility.

Key words: Mobility model; vehicular networks; urban traffic simulation; mobility traces.

\section{Introdução}

Táxis, como uma das principais modalidades de transporte em grandes centros urbanos, são de grande interesse na área de pesquisa de redes veiculares, conhecidas como Vehicular Ad hoc NETworks (VANETs) Zhang et al. (2012). Em geral, os táxis possuem um padrão de movimento influenciado pelo comportamento dos motoristas e interesses de seus passageiros. Esse comportamento sofre alterações ao longo do dia bem como durante os dias da semana Cunha et al. (2015). No contexto de redes veiculares, esse padrão pode desempenhar um papel importante na comunicação inter-veicular, já que os táxis estão distribuídos ao longo da cidade, influenciando no roteamento das mensagens da rede.

Um modelo de mobilidade visa representar a movimentação e o comportamento de elementos do mundo real, de modo a possibilitar que protocolos de rede sejam testados em um ambiente de simulação o mais próximo possível do mundo real. Dessa maneira, é possível identificar problemas e analisar o comportamento do protocolo com maior precisão, controlando, por exemplo, o número de elementos da rede, o tipo e a quantidade de mensagens enviadas. A simulação possibilita repetir o processo inúmeras vezes, até alcançar os objetivos almejados. Os modelos de mobilidade podem ser totalmente sintéticos, mas também podem incorporar 
características extraídas diretamente de observações reais da movimentação de um grupo de veículos. Este artigo foca nos modelos que simulam a movimentação de veículos e, mais especificamente, em táxis em um grande centro urbano.

$\mathrm{O}$ artigo está organizado da seguinte forma: as seções 2 e 3 descrevem o contexto desse artigo; em seguida, nas seções 4, 5 e 6 são apresentadas as bases de dados e ferramentas empregadas no desenvolvimento desse artigo; a seção 7 apresenta os trabalhos relacionados; a metodologia e o desenvolvimento são apresentados na seção 8; e, por fim, os resultados obtidos são descritos na seção 9 e as conclusões na seção 10 .

\section{Vehicular Ad-hoc NETworks - VANETs}

Redes ad hoc veiculares (Veihicular Ad hoc NETworks, VANETs) são uma especialização da classe de redes ad hoc móveis (Mobile Ad Hoc NETworks, MANETs). Uma MANET é uma rede móvel independente de uma infraestrutura fixa para estabelecer a comunicação entre os nodos. A movimentação dos nodos pode resultar em mudanças frequentes na topologia da rede, exigindo que os nodos se auto organizem para trocar mensagens entre si.

Em uma rede VANET existem algumas características que devem ser levadas em consideração no momento da escolha, ou do desenvolvimento, de um protocolo para a camada de rede. Além das prováveis alterações frequentes na topologia da rede, o movimento é intensamente influenciado por variáveis do meio onde os veículos estão se locomovendo (e.g., ruas, paradas em semáforos, congestionamento e tipos de vias). Essas características podem inviabilizar completamente o funcionamento da rede se for utilizado um protocolo de rede convencional, mesmo aqueles que apresentam bom desempenho em outros tipos de redes sem fio.

Uma rede VANET pode ser composta por diversos tipos de veículos (e.g., carros de passeio, táxis, caminhões, ônibus) todos trocando informações entre si enquanto se movimentam. Esse tipo de rede pode alertar os motoristas de congestionamentos ou até prevenir acidentes. Um problema desse tipo de rede sem fio é que há um grande percentual de perda de pacotes e atrasos no envio de mensagens, possivelmente requerendo transmissões em múltiplos saltos para que a mensagem trafegue da origem até o destino.

\section{Modelos de mobilidade}

Um modelo de mobilidade é uma especificação, ou uma descrição, de como entidades móveis se movimentam em um determinado ambiente. Os modelos de mobilidade podem representar a movimentação individual de cada entidade, mas também podem descrever uma dependência temporal e espacial entre esses indivíduos. Nas VANETs, as entidades se movimentam respeitando, primeiramente, as ruas da cidade e a sinalização de trânsito, adaptando sua movimentação em consonância a outras entidades presentes no mesmo ambiente.
Conforme A. Hess et al. Hess et al. (2015), os modelos de mobilidade podem ser elaborados baseados em hipóteses sobre determinadas propriedades do movimento como, por exemplo, velocidade ou mudança de direção. Tradicionalmente, esses modelos são classificados como modelos sintéticos, onde se incorporam modelos matemáticos que reproduzem características do mundo real.

Nos últimos anos, houve um grande crescimento da disponibilidade de bases de dados de traços reais de mobilidade (e.g., Bracciale et al. (2014)), bem como o enriquecimento e aprimoramento de bases abertas de mapas de cidades, incluindo além do detalhamento acerca das vias públicas, informações sobre edifícios, pontos turísticos, pontos de transporte urbano, dentre outras informações úteis às pessoas.

Os traços de mobilidade podem ser lidos e armazenados por sistemas GPS, ou até mesmo roteadores $\mathrm{Wi}-\mathrm{Fi}$ de uma instituição ou organização; porém, acarretam em um custo de armazenamento e processamento consideráveis. A maior disponibilidade de traços veiculares e o aprimoramento das bases de dados geográficos impulsionaram o surgimento de modelos de mobilidade veicular "realísticos" que imitam a movimentação real de indivíduos e comportamentos em ambientes específicos de maneira mais confiável que nos modelos puramente sintéticos. Esses modelos são desenvolvidos através da extração, ou generalização, de características observadas nos traços de mobilidade reais e podem representar mais facilmente a movimentação real dos elementos da rede do que os modelos sintéticos. Os traços de mobilidade podem ser combinados com os mapas reais para compreender melhor o comportamento e proporcionar uma análise mais aprimorada da movimentação observada.

\subsection{Modelos sintéticos}

Dentre os modelos sintéticos, um dos mais empregados em simulações é o Random Waypoint (RWP) Saha and Johnson (2004). Nesse modelo, cada indivíduo escolhe um destino aleatório dentro da área delimitada para a simulação, definindo-se também uma velocidade aleatória, entre os limites mínimos e máximos definidos e, logo em seguida, movimenta-se até o destino escolhido. Quando alcança seu destino, o nodo pode pausar por um tempo determinado e, em seguida, repetindo-se o procedimento anterior. A Figura 1 representa graficamente o padrão de deslocamento de um nodo segundo o RWP. O RWP é semelhante ao modelo Random Walk Camp et al. (2002), caso considerássemos um tempo de pausa igual a zero. Um dos problemas deste modelo, e de outros com limitações de espaço de movimentação, é que os nodos tendem a convergir para o centro da área de simulação, causando má distribuição das entidades móveis. Alguns modelos subsequentes foram propostos para tentar resolver esse problema (e.g., Boundless Simulation Area) Saha and Johnson (2004).

O RWP não traz nenhuma semelhança com a mobilidade de veículos, não se apresentando como uma boa escolha para a simulação de protocolos de 


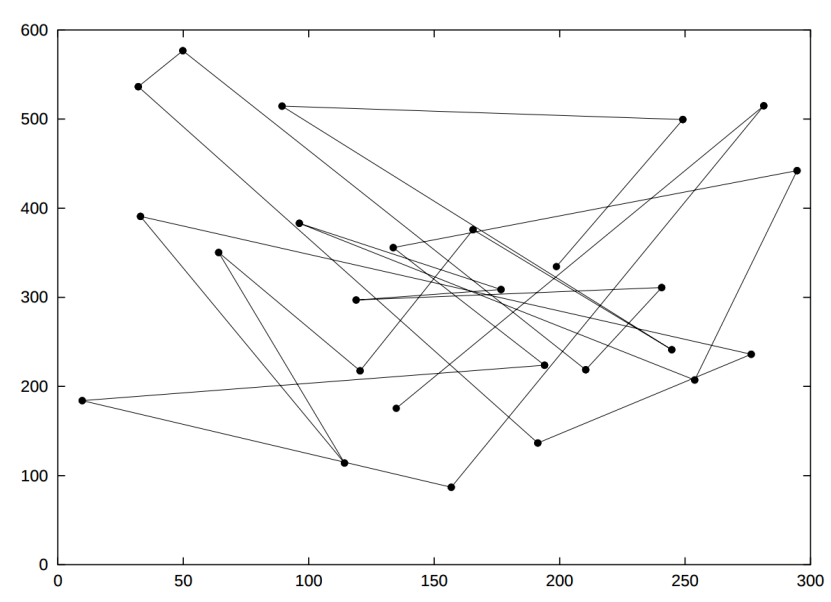

Figura 1: Movimentação segundo o modelo Random Waypoint em uma região correspondente a uma área de 300 m X 600 m (adaptado de Camp et al. (2002))

redes veiculares. Um modelo sintético que representa uma tentativa de simular mais realisticamente a movimentação de veículos em uma cidade é o City Section Mobility Model Camp et al. (2002). Neste modelo, a área de simulação limitada por uma "rede" de ruas, representando uma seção da cidade onde opera a rede ad hoc. Neste modelo, a velocidade pode variar dependendo do tipo de região da cidade sendo simulada. Altera-se também o padrão das ruas, representando regiões residenciais por uma grade e regiões mais externas por ruas mais extensas. Cada nodo começa a simulação em um ponto de uma determinada rua, tendo-se então um destino definido, também representado por um ponto em uma outra rua. Após isso, o nodo se movimenta pelas ruas até o destino pelo menor caminho encontrado, respeitando limites de velocidade e distância mínima entre os veículos. Quando alcança o destino, o nodo pára por alguns instantes e repete o processo. No entanto, esse modelo sintético não descreve o comportamento em intersecções, acelerações, desacelerações e congestionamentos, mas serviu de base para a proposta de diversos modelos mais realísticos. A Figura 2 apresenta um exemplo de movimentação de um nodo segundo esse modelo.

\section{Open Street Map}

O Open Street Map (OSM) é uma base de dados geográfica aberta onde qualquer pessoa pode contribuir com informações relativas a qualquer lugar do planeta. É um dos melhores exemplos do campo de Informação Geográfica Voluntária (Volunteered Geographic Information - VGI) Neis et al. (2011). O OSM foi criado seguindo a filosofia de produção do Wikipedia, objetivando criar um conjunto de dados de mapas do mundo inteiro de forma gratuita para uso, edição e licenciado de acordo com novos esquemas de copyright. O projeto, nascido na University College London (UCL) em Julho de 2004, foi fundado por Steve Coast.

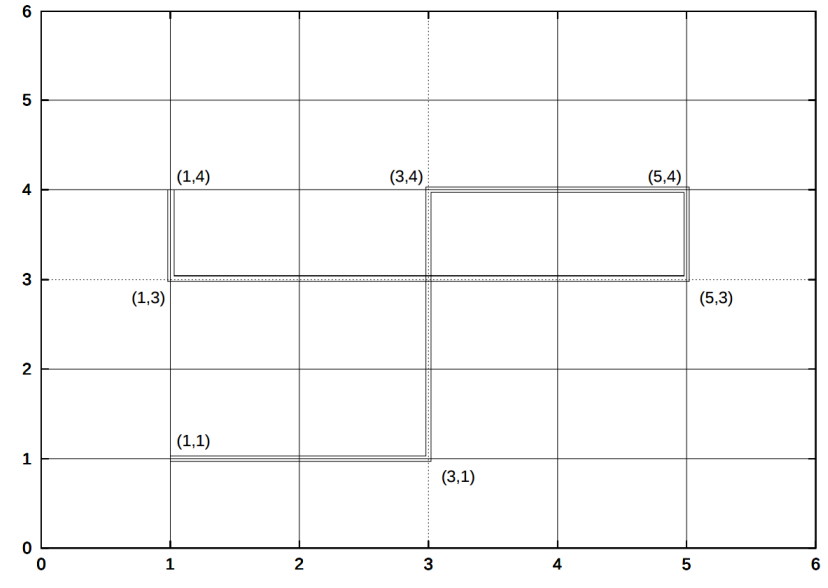

Figura 2: Exemplo de movimentação segundo o modelo City Section (área ilustrada corresponde a uma "rede" de ruas - adaptado de Camp et al. (2002))

\subsection{Estrutura dos dados}

O OSM utiliza um modelo de dados muito simples, mas ao mesmo tempo flexível, focando na facilidade de edição pelo usuário. Existem, basicamente, três tipos de dados principais Göbelbecker et al. (2009):

- Nodos: possuem um ID e a localização, representada pelas coordenadas de latitude e longitude;

- Caminhos/formas: consistem em uma lista ordenada de nodos. Dependendo do contexto, podem representar uma linha (uma rua) ou uma área.

- Relações: contém um número arbitrário de outras primitivas (incluindo outras relações) e podem ser utilizados para modelar estruturas mais complexas.

O OSM disponibiliza os modelos dos mapas em XML; portanto, todos os dados são codificados em tags, pares de atributos e valores onde cada primitiva pode ter um número ilimitado de atributos. As tags são bastante arbitrárias, padronizadas ao longo das versões para representar informações comumente utilizadas.

A maioria das características dos mapas são representadas utilizando-se apenas um pequeno número de tags como, por exemplo, um caminho com um atributo/valor do tipo highway="footway", representando uma rua para pedestres e, opcionalmente, um nome empregando a diretiva name="Fernando Machado".

\section{Base de traços de mobilidade veicular}

O CRAWDAD Kotz et al. (2009) é uma extensa base de dados de mobilidade, coletados com o auxílio de colaboradores. Em particular, este artigo utiliza a base de dados dos táxis de Roma/Itália Bracciale et al. (2014). Nessa base de dados foram acompanhados aproximadamente 320 táxis no centro de Roma. A localização de cada veículo (obtida via GPS) foi armazenada, aproximadamente, a cada $7 \mathrm{~s}$. Os dados foram coletados no período de 01/02/2014 à 
02/03/2014, mantendo-se apenas os registros com precisão menor que $20 \mathrm{~m}$. A base possui um total de 21.817.851 registros.

Cada registro dessa base de traços de mobilidade é composto por:

- ID: Identificação do táxi (o nome real foi substituído pelo ID para preservar a identidade de cada motorista).

- Timestamp: Data e hora em que o registro foi coletado.

- Posição geográfica: Posição obtida via GPS, representada por POINT(latitude, longitude).

Por exemplo, o registro 59; 2014-02-01 oo:00:03.707117+o1; $\quad \operatorname{POINT}(41,8967831636848$ 12,4821987021152) representa a posição do Táxi 59, à meia noite (e 3s) do dia 01/02/2014, na posição com latitude 41,8967831636848 e longitude $12,4821987021152$.

Nesta pesquisa, para uma análise inicial, os dados foram inseridos em um banco de dados SQL, ignorando-se registros de um mesmo táxi onde o timestamp da posição tivesse menos de 1 $\mathrm{s}$ em relação ao anterior. Foi possível observar que, em média, existem 67.519 registros por táxi, sendo que o máximo por táxi é de 116.198 registros. Não há registros para todos os táxis em todos os dias e horários. Os dados são armazenados em determinados horários do dia e, possivelmente, refletem o horário de trabalho de cada motorista.

Um aspecto relevante que deve ser levado em consideração ao analisar esse tipo de base de dados, refere-se ao fato que a informação fornecida por dispositivos GPS pode apresentar erros significativos. Há, por exemplo, o efeito ping pong Zhang et al. (2012), que ocorre quando o equipamento GPS está associado a uma referência e, em um intervalo de tempo muito curto, muda a associação (i.e., como se ocorrera um deslocamento a uma distância muito grande em um curto intervalo de tempo). Esse erro é relativamente frequente em muitos dispositivos GPS. Nesse caso, uma estratégia que pode ser adotada consiste em definir uma velocidade máxima permitida, ignorando traços que excedam a velocidade limite Zhang et al. (2012).

Cunha et al. (2015) analisaram a base de dados de traços de táxis coletados nas cidades de Roma (Itália) e São Fransisco (EUA). Na análise, objetivouse identificar as características das interações entre os veículos. A análise foi realizada empregandose grafos temporais, representando-se cada veículo como um vértice no grafo e as arestas representando um enlace entre dois veículos quando dentro do raio de comunicação um do outro. Empregou-se alcances de transmissão do rádio de $100 \mathrm{~m}$ e $150 \mathrm{~m}$, assumindose o protocolo IEEE 802.11p. No processo de análise, definiram-se as seguintes métricas de interações:

- Veículos e calendário: representa a variação da densidade do tráfego ao longo dos horários e dias da semana (vide Figura 3).

- Veículos, pessoas e calendário: representa a variação da frequência de encontro de veículos ao longo do dia. Pessoas que possuem rotinas similares geralmente apresentam um índice maior de frequência de encontro. Por exemplo, em dias úteis a taxa de encontro é muito maior que
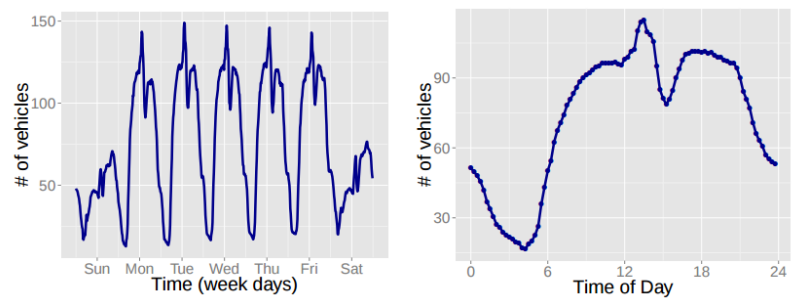

Figura 3: Número de veículos semanalmente e diariamente (adaptado de Cunha et al. (2015))

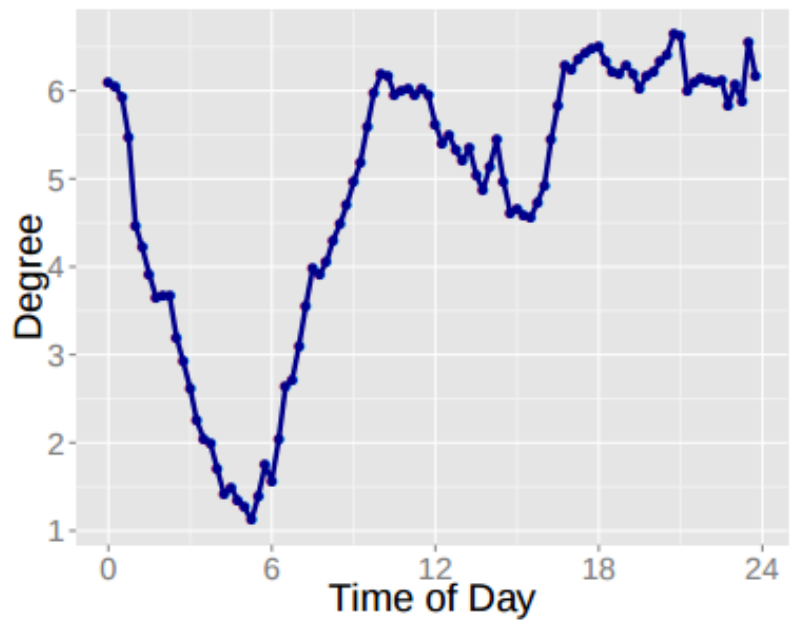

Figura 4: Grau de conectividade dos táxis de Roma ao longo do dia, assumindo um alcance de $150 \mathrm{~m}$ (adaptado de Cunha et al. (2015))

em finais de semana. Para calcular esse tipo de interação, computou-se os graus dos nodos e a persistência dos enlaces (vide Figuras 4 e 5).

- Veículos, pessoas e lugares: Essa interação contempla os horários do dia com o maior número de veículos em trânsito, bem como os lugares mais visitados da cidade ou o tipo de lugar que as pessoas tem maior preferência para visitar. Por exemplo, captura o comportamento em horários de almoço, momento em que um número maior de pessoas saem do local de trabalho e dirigem-se a locais com maior concentração de restaurantes. Para extrair essas informações do grafo temporal, computaram-se as métricas distância, coefieciente de agrupamento e sobreposição de topologia (do inglês: topology overlap).

\section{Simulador de mobilidade urbana}

O Simulation of Urban Mobility (SUMO) ${ }^{1}$ Krajzewicz et al. (2012) é um sistema de código aberto para simulação de tráfego, desenvolvido no Instituto de Sistemas de Transportes do Centro Aeroespacial Alemão. Além do próprio simulador de eventos discretos, disponibilizam-se diversas ferramentas para auxiliar na preparação e manipulação da

${ }^{1}$ Disponível em: http://sumo.dlr.de/wiki/ 


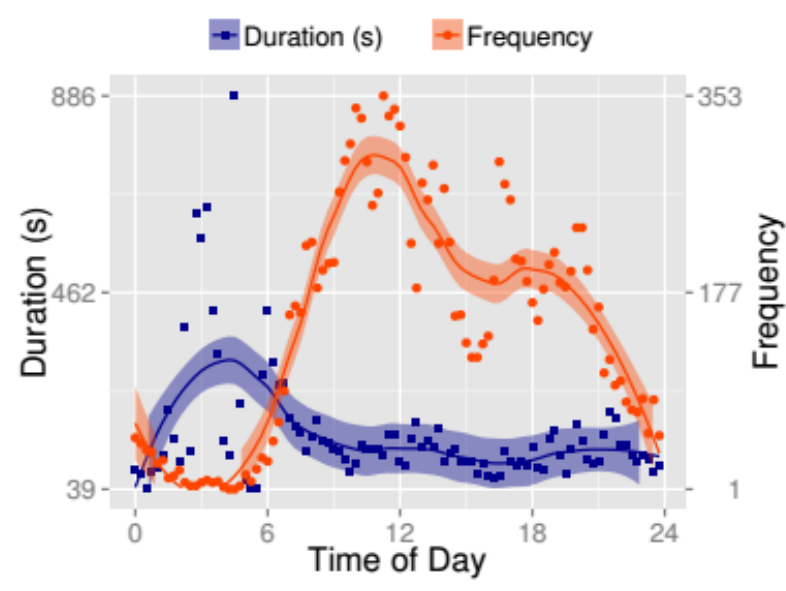

Figura 5: Frequência e duração de encontros entre veículos ao longo do dia (adaptado de Cunha et al. (2015))

simulação.

Empregado em diversos segmentos de pesquisa, principalmente na área de comunicação veicular e gerenciamento de tráfego, o SUMO é um simulador "microscópico"; ou seja, cada veículo é modelado explicitamente. Diversos modelos independentes são utilizados para definir diferentes aspectos da dinâmica do movimento de cada um dos veículos.

O SUMO permite que a simulação seja controlada através do Traffic Control Interface (TraCI)Wegener et al. (2008), um sistema cliente/servidor baseado em TCP. Através dessa comunicação é possível ler informações da simulação e manipular estados de objetos durante a execução da simulação (e.g., estado de uma rua, de um semáforo, de um veículo). Esse tipo de interface de controle permite o acoplamento da simulação de tráfego com a simulação de rede, onde eventos de uma simulação impactam diretamente na outra simulação. Para facilitar esse acoplamento, algumas ferramentas foram desenvolvidas especialmente para o SUMO como, por exemplo, o Veins Sommer et al. (2011), que é um framework para a simulação bidirecional entre o SUMO e o OMNeT++Varga (1999).

O SUMO possui ferramentas para auxiliar a preparação da rede (mapa) da simulação como, por exemplo, as seguintes:

- netconvert: Importa mapas de diversas fontes (e.g., OSM).

- netedit: Permite a edição de um mapa do SUMO ou a criação de um mapa sintético.

- netgenerate: Possibilita a geração de três tipos de mapas sintéticos Krajzewicz et al. (2012):

- Grade;

- "Teia de aranha circular";

- Aleatório.

O netconvert lê um mapa exportado do OSM e converte para o formato utilizado pelo SUMO. Esse formato é, basicamente, uma rede de vértices interligados por arestas, simbolizando as ruas do mapa com diversas propriedades (e.g., prioridade, velocidade, número de pistas, comprimento). As formas geométricas são importadas pelo polyconvert e representam outros aspectos do mapa (e.g., rios, prédios, praças). A figura 6 ilustra o resultado da importação de uma parte do mapa da cidade de Roma (Itália).

\section{Trabalhos Relacionados}

Identificam-se duas abordagens de trabalhos relacionados. A primeira, trata-se de modelos gerados a partir de dados geográficos de mapas, impondo-se restrições geográficas para a movimentação dos veículos da rede. Na segunda, introduz-se modelos baseados na observação de traços reais de mobilidade, podendo ser classificada como uma especialização da primeira abordagem. Nesse caso, a movimentação e o comportamento dos veículos são baseados em estatísticas reais. Analisa-se, por exemplo, a probabilidade de um veículo utilizar determinada rua do mapa para chegar em um determinado destino, bem como a velocidade média para uma determinada localização em um horário e dia da semana específicos.

O modelo City Section (introduzido na seção 3.1) foi um dos primeiros a tentar representar mais realisticamente a movimentação de veículos em uma rede. Uma melhoria desse modelo foi o Street Mobility Model Saha and Johnson (2004), que foi, segundo os autores, o primeiro a analisar características de um modelo realístico de movimentação em ruas. O modelo utiliza diretamente ruas da base de dados dos mapas dos Estados Unidos, disponibilizada publicamente e conhecida como Topologically Integrated Geographic Encoding and Referencing (TIGER) do U.S. Census Bureau Street Map Data.

No City Section, as ruas precisam ser definidas pelo usuário, dificultando o uso do modelo. O Street Mobility Model primeiro cria o cenário da simulação através do mapa, gerando um grafo com pontos conectados por arestas representando as ruas da cidade. Em seguida, cada nodo (veículo) da rede é posicionado em um ponto aleatório do cenário de simulação. Um destino aleatório é estabelecido e o percurso é computado aplicando-se um algoritmo para encontrar o caminho mais curto (e.g., algoritmo de Dijkstra). No grafo gerado para representar o mapa, cada aresta (rua) possui um peso relativo à velocidade máxima permitida na via, sendo que esse peso é dinamicamente ajustado de acordo com o número de veículos trafegando na via. Desta forma, permite-se aos veículos alterarem o trajeto durante o percurso até o destino, refletindo sempre o caminho, momentaneamente, mais rápido. A velocidade do veículo é estabelecida de acordo com o tipo de via representada na base de dados, contemplando-se uma variação de \pm 5 do limite da via. Toda vez que um veículo chega ao destino, um novo destino é computado para dar continuidade à simulação. Nesse modelo, no entanto, não se permite representar sinais de trânsito nem a interação direta entre os veículos, mas apenas uma redução no interesse pelos demais veículos por vias com alta concentração.

Dentre os modelos baseados em traços reais, podese citar o MEtropolitan TAxis (META) Huang et al. (2010) que é um modelo de mobilidade baseado nos traços de táxis da área central da cidade de Xangai, 


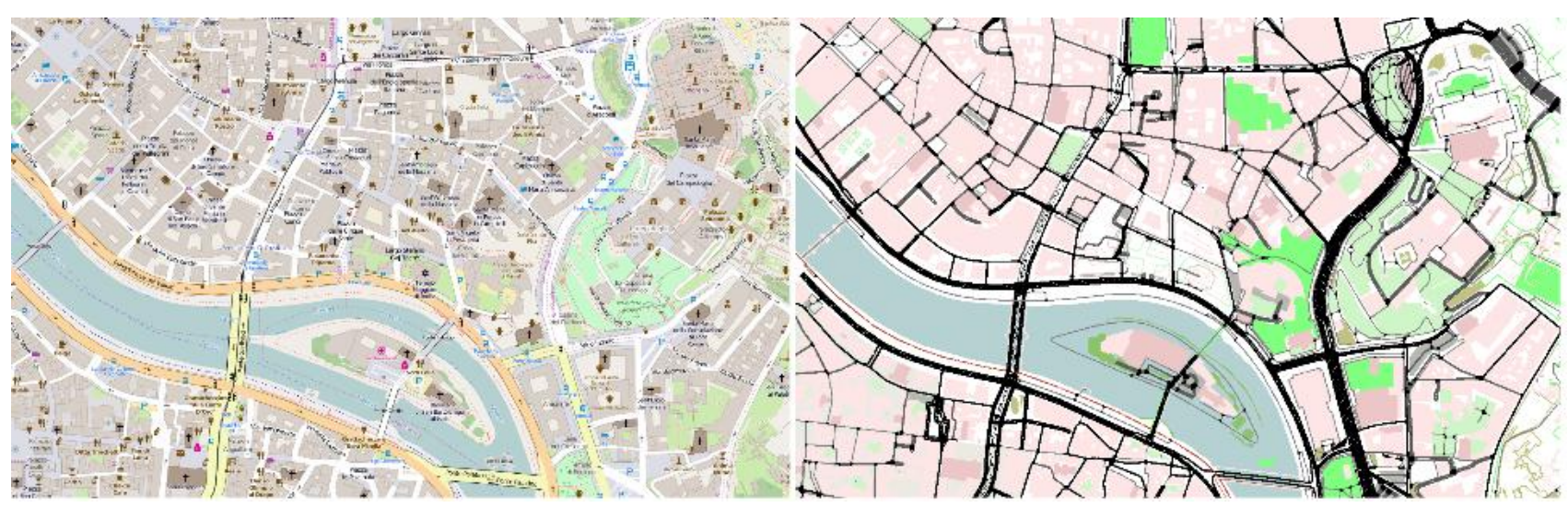

Figura 6: Resultado da importação para o SUMO de parte de um mapa (do OSM) da cidade de Roma/Itália

na China. Esses traços contém dados de mais de

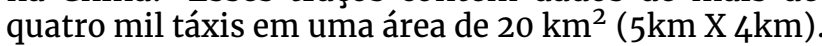
Em média, existe um registro da posição de cada táxi a cada minuto, coletados durante um período de três meses. Cada registro da base de traços contém as seguintes informações: ID do táxi; timestamp; coordenada geográfica; direção, representada pelo ângulo em graus a partir do norte geográfico; flag indicando se o táxi está transportando um passageiro.

Essa base possui mais informações se comparada com a base de Roma, adotada neste trabalho. No entanto, para o objetivo proposto, as informações adicionais não seriam relevantes ao resultado final.

Para o desenvolvimento do META, foram observadas as seguintes características:

- Turn Probability: probabilidade de um veículo mudar de direção em uma determinada esquina, considerando-se todas as oportunidades que um veículo passou por ela.

- Road Section Speed: a média da velocidade de um táxi em um determinado trecho de uma rua em um período de 5 minutos. Considerou-se a média devido ao grande intervalo entre registros, impossibilitando o cálculo preciso da velocidade do veículo em um instante específico.

- Travel Pattern: os táxis possuem uma característica de movimento microscópica, representada pelo comportamento em relação à velocidade e interação com outros veículos e o meio. O Travel Pattern analisa macroscopicamente o comportamento dos táxis, interpretando a preferência que um táxi tem para se deslocar à uma determinada região. Para analisar essa propriedade, o mapa da cidade foi dividido em regiões de $1 \mathrm{~km}^{2}$, calculando-se a distribuição de origens e destinos das viagens dos táxis.

O modelo foi implementado da seguinte maneira: antes do nodo iniciar a movimentação, escolhe-se aleatoriamente a origem e destino, identificados pela região de $1 \mathrm{~km}^{2}$ no mapa; em seguida, define-se o caminho com a maior probabilidade (i.e., Turn Probability) e dá-se início à movimentação. A velocidade do veículo é baseada no cálculo do Road Section Speed Madi and Al-Qamzi (2013).

Um outro modelo Zhang et al. (2012), também baseado na mesma base de traços de Xangai, caracteriza a movimentação dos táxis analisando probabilidades de transições entre diferentes regiões (igualmente mapeadas em áreas de $1 \mathrm{~km}^{2}$ ). Dentro de cada região, modela-se a movimentação de cada táxi individualmente, levando-se em consideração o horário do dia. Zhang et al. (2012) afirmam que esse modelo é melhor que o META porque não considera apenas o centro da cidade na modelagem. Como diferencial, adotaram-se duas métricas de tráfego: Vehicle Kilometers Traveled (VKT) e Accumulative Residence Time (ART). A primeira é, geralmente, utilizada na engenharia de transportes e refere-se à distância percorrida pelos veículos nas estradas. A segunda serve para calcular o tempo de permanência dos veículos em cada região. Por exemplo, lugares como aeroportos possuem táxis que permanecem tempo considerável parados aguardando um novo cliente; já, em contrapartida, no centro da cidade esse comportamento pode ser diferenciado, considerandose que a concentração de pessoas é mais acentuada.

Para caracterizar a movimentação, esse modelo identificou regiões "quentes" do mapa, mapeandose locais com níveis de VKT e ART mais significativos. Além disso, computa-se a probabilidade e o tempo de viagens entre regiões do mapa. Nesse processo, geraram-se cinco grandezas básicas para criar os traços: probabilidade de transição entre regiões, distribuição do tempo de transição entre cada região, distribuição da concentração de tráfego em cada região, tempo e velocidade de viagem entre regiões. Para gerar os traços de um único táxi, o modelo começa selecionando um local aleatório no início do dia (zero horas) e, em seguida, emprega-se a probabilidade de transição para determinar a rota na cidade. Para cada uma das regiões da rota, utiliza-se a distribuição do tempo de transição e da concentração do tráfego para determinar o tempo que o táxi permanece em cada região. Esse processo foi repetido para gerar traços de 4000 táxis em um dia completo.

\section{Metodologia e desenvolvimento}

Inicialmente, procedeu-se com a análise dos padrões de mobilidade dos traços da base de dados escolhida (descrita na seção 5). O objetivo é extrair a distribuição de origens e destinos das viagens dos táxis. Para tanto, os traços foram mapeados em regiões de no máximo $1 \mathrm{~km}^{2}$, conforme realizado na 
implementação do META Huang et al. (2010). Desta forma, torna-se possível calcular a probabilidade de um táxi sair de uma região e se deslocar a outra, identificando também as regiões mais prováveis por onde um táxi cruza para alcançar o destino.

Utilizando-se o OSM, torna-se possível identificar os pontos de táxis cadastrados pelos colaboradores do projeto. Esses pontos foram utilizados para uma análise inicial das viagens. Adicionalmente, identificou-se no mapa os prováveis pontos de atração para os deslocamentos dos táxis (e.g., igrejas, praças, museus, monumentos, rodoviárias, aeroportos), graduando-se a relevância desses pontos pela quantidade de deslocamentos observados. Em síntese, combinando os traços reais e os dados do OSM, identificou-se os seguintes pontos:

- Pontos de origens das viagens;

- Pontos de atração (destinos de viagens).

A fim de tornar o problema mais tratável, levouse em consideração apenas os dias úteis da semana (de segunda à sexta-feira), segmentados em três horários: 07:00 às 09:00, 11:00 às 14:00 e 17:00 às 19:00. Considerou-se também apenas os 10 táxis com mais registros na base de dados.

A partir desses dados já é possível desenvolver um algoritmo gerador de rotas de táxis, produzindo-se metadados relativos aos percursos de cada um dos táxis da simulação. O algoritmo deverá atribuir aos táxis os pontos de partida das viagens, computandose o caminho até o destino estabelecido. Como o tráfego é simulado no SUMO, não será necessário se preocupar com o comportamento dos táxis em relação às ruas, sinais de trânsito e outros veículos. Esse simulador implementa diversos modelos para representação da movimentação dos veículos, inclusive o controle dos semáforos. 0 processo consiste em um conjunto de aplicativos que convertem a matriz de origens e destinos em rotas para o táxi se deslocar pelo mapa, sendo que alguns desses programas já fazem parte do SUMO e são aplicados para auxiliar no processo.

Com o gerador de rotas desenvolvido, torna-se possível realizar simulações para validar o modelo. Os dados sintéticos gerados pela simulação no SUMO podem ser confrontados com os traços reais da base de dados de Roma. Para a extração dos traços do simulador, o SUMO foi configurado para registrar em um arquivo a posição geográfica de cada veículo em cada instante de tempo da simulação.

A análise dos dados foi realizada com o auxílio das ferramentas de análises de traços $\mathrm{M}$-Atlas ${ }^{2}$ e QGIS $^{3}$. Os dados foram convertidos no formato reconhecido pelas ferramentas e foram extraídas algumas métricas da movimentação como, por exemplo:

- Distribuição das velocidades em diferentes horários do dia;

- Matriz de origens e destinos;

- Comprimento médio das viagens;

- Heatmap da concentração de táxis;

- Número de táxis ativos.

\footnotetext{
${ }^{2}$ Disponível em: http://m-atlas.eu/

3Disponivel em: https://www.qgis.org/
}

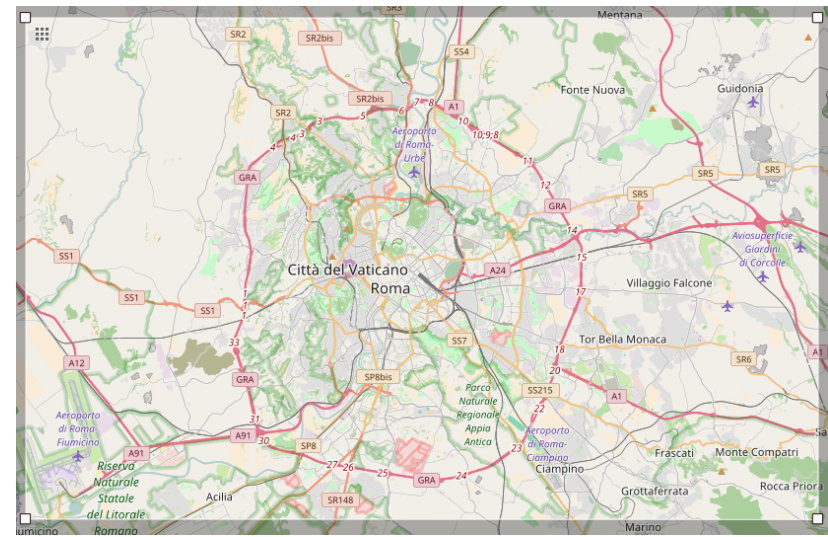

Figura 7: Área considerada para a conversão do mapa do OSM para o formato de rede do SUMO

Os traços reais passaram por uma filtragem para suavizar os erros comuns em localização via GPS. O $M$-Atlas fornece diversos parâmetros para que isso seja realizado na hora de computar os trajetos de cada táxi.

Os dados gerados foram registrados, analisados e calibrados diversas vezes de modo que seja possível chegar o mais próximo possível das características dos traços reais.

\subsection{Preparação do mapa}

O mapa original do OSM foi obtido através da API do site considerando os extremos das regiões identificadas pelo $\mathrm{M}$-Atlas. Em coordenadas geográficas, esses pontos são representados por (latitude/longitude): 12,2285/41,774, 12,7804/42,0336 (região ilustrada na Figura 7). A área total tem aproximadamente $28 \mathrm{~km} \mathrm{x} 61 \mathrm{~km}$ $\left(1708 \mathrm{~km}^{2}\right)$.

O mapa em questão possui muitas informações desnecessárias para a simulação, conforme detalhado na seção 4. Nesse contexto, removeu-se as seguintes vias consideradas irrelevantes para a geração das rotas da simulação: railway.\{funicular, monorail, narrow_gauge, preserved, subway, light_rail, rail\}, highway.\{steps, bridleway, footway, cycleway, $\bar{p}$ ath, track, service, pedestrian, living_street, road, residential, unclassified\}, bus_guideway. A mesma rede foi gerada mantendo todas as ruas, mas foi utilizada apenas durante a simulação, quando todos os trajetos já estavam computados.

\subsection{Identificação dos padrões}

Selecionaram-se 10 táxis, ordenados decrescentemente pela quantidade de registros nos traços originais. Desse conjunto de táxis, foram selecionadas rotas para identificação dos padrões ao longo de três intervalos de horários: das 07:00 às 09:00, das 11:00 às 14:00 e das 17:00 às 19:00. A análise foi realizada dessa maneira para otimizar o custo, pois utilizar todos os dados demandaria um processamento e tempo talvez indisponíveis para conclusão dessa pesquisa.

No total, foram considerados 305.417 registros, dos quais 61.907 estavam no primeiro intervalo de 
horário, 108.460 no segundo e 135.050 no terceiro. No M-Atlas os registros são convertidos para trajetos, ou MOVING POINTS, de acordo com diversas opções de filtro disponíveis. As rotas foram filtradas utilizando as seguintes opções:

- MAX_TIME_GAP: um novo trajeto é criado se o tempo entre registros ultrapassar 60 segundos.

- MAX_SPACE_GAP: caso a localização de um registro estiver a mais de $500 \mathrm{~m}$ do registro anterior, este registro será ignorado, seguindo para o próximo. Esse parâmetro resolve o problema do efeito ping-pong, comum em dispositivos GPS.

- MAX SPEED: caso o cálculo da velocidade ultrapassar os $130 \frac{\mathrm{km}}{\mathrm{h}}$, o registro será considerado ruído e ignorado.

Com os trajetos carregados e filtrados no $\mathrm{M}$ Atlas, a ferramenta T-Pattern Giannotti et al. (2007) (incorporada ao $\mathrm{M}$-Atlas) foi empregada para análise dos padrões. O M-Atlas converte os dados geográficos para o padrão de entrada do T-Pattern, o qual identifica as temporally-annotated sequences (TAS). Em sequência, o M-atlas processa esse retorno, salvandoo no banco de dados (PostgreSQL+PostGIS). Com essa ferramenta, torna-se possível identificar as regiões de interesse (Region of Interest, ROI) e, a partir delas, o padrão de movimentação ao mover-se de uma ROI para outra. Esse padrão é denominado de TAS , levando-se em consideração tempo e espaço na identificação do padrão. Uma ROI representa uma região de, no máximo, $1 \mathrm{~km}^{2}$. Um TAS é uma sequência de transições entre regiões com uma anotação de tempo. Para a identificação do padrão, definiu-se um threshold de $10 \mathrm{~min}$, mantendo-se apenas os padrões que se repetiram pelo menos $6 \%$ no intervalo das 07:00 às 09:00, 3,5\% no intervalo das 11:00 às 14:00 e 2,5\% no intervalo das 17:00 às 19:00. Essa variação na porcentagem ocorre devido ao limite de processamento e memória empregados no processo. Caso o valor do percentual for elevado, vários possíveis padrões passariam despercebidos, enquanto que valores menores impossibilitariam o processamento com os recursos disponíveis.

Os dados de interesse (i.e., ROI e TAS identificados) foram salvos em um banco de dados PostgreSQL, configurado com a extensão PostGIS. Esses dados foram processados com programas desenvolvidos em linguagem Python, de modo a convertê-los para um formato aceito pelo SUMO. Inicialmente, as regiões de interesse foram identificadas e isoladas para que fosse possível determinar os distritos, necessários para a geração de trajetos no SUMO. Um distrito consiste em uma região qualquer onde são definidas as ruas que servem como entrada (source) e saída (sink). No SUMO uma rua é definida por diversas arestas (edges), cada uma com um ID gerado no momento da conversão do mapa original para a rede do SUMO. Para criar esses distritos, implementou-se o seguinte algoritmo:

$\mathrm{O}$ formato original gerado pelo $\mathrm{M}$-Atlas armazena apenas uma sequência de polígonos e tempos (sem normalização do banco), seguidos dos tempos (máximo e mínimo) de transição entre cada polígono e o número de vezes que este padrão se repetiu.

Para possibilitar o procedimento descrito anteriormente, extraiu-se os polígonos (ROI) em uma tabela auxiliar com as seguintes colunas:
Result: Distritos com arestas de entrada/saída for cada aresta não-interna da rede do

for cada região salva no banco de dados do if $a$ aresta está geograficamente dentro da região then

Adicione a aresta como source do distrito identificado pelo ID da end região; end

end

Algorithm 1: Algoritmo para identificação das ruas que servem de entrada/saída de uma ROI

region_id e polygon. O polígono é representado por quatro pontos compostos por latitude e longitude, indicando os cantos do quadrado. Uma segunda tabela foi criada para salvar os trajetos originais, contemplando as seguintes colunas:

- pattern_id: ID único do padrão;

- start_region: região inicial;

- end_region: região final;

- travel_time: tempo de transição entre as regiões (mantendo-se o máximo apenas);

- $i$ : número sequencial, caso o padrão contenha transições entre várias regiões.

O número de repetições de cada padrão foi armazenado em outra tabela, contendo o ID da região e a contagem de repetições. Essa informação é relevante para determinar a importância de cada padrão identificado. Mais repetições indicam que diversos táxis percorrem aquele trajeto com aquele tempo nos períodos analisados.

\subsection{Geração dos trajetos baseado nos padrões}

Uma vez que todas as regiões foram mapeadas e os distritos definidos, foi possível criar uma matriz de origens e destinos (Matriz O/D), contendo o distrito inicial e final, incluindo a quantidade de veículos no trajeto. O número de veículos foi definido como sendo proporcional ao número de repetições do padrão. Por exemplo, para uma entrada com 500 veículos, estes serão distribuídos proporcionalmente de acordo com a importância de cada padrão. Nesse processo foi fixado um número mínimo de veículos para padrões muito insignificantes, de modo a evitar situações sem algum trajeto.

O padrão de matriz O/D não permite que sejam especificadas as transições entre várias regiões; neste caso, quando um padrão possui várias regiões de transição, manteve-se apenas a primeira região e a última, ignorando as transições intermediárias. Essa escolha deu-se a partir da suposição de que as "pontas" dos trajetos são de fato os pontos de interesse no mapa, enquanto as regiões intermediárias são apenas lugares que os táxis costumam circular com frequência para chegar aos destinos. Assumiu-se que os taxistas escolham trajetos otimizados para alcançar os destinos, de forma semelhante ao realizado pelo SUMO que escolhe caminhos melhores baseados nos tipos de ruas. 
O padrão de tempo de transição entre regiões foi ignorado na geração dos fluxos dos táxis. Esse tempo é baseado em diversos fatores como, por exemplo, a quantidade de outros veículos (i.e., que não são táxis) e tempos de semáforos. Não há como precisar exatamente quantos veículos estão circulando em conjunto com os táxis. Para simular esse "fator limitante", criaram-se vários trajetos aleatórios para os demais veículos, adotando-se as categorias passenger e private do SUMO.

Após a geração das rotas, inseriu-se paradas em posições aleatórias ao longo do trajeto, com duração variando de $30 \mathrm{~s}$ a dois minutos. Isso foi adicionado para simular mais adequadamente, porém muito incipientemente, o comportamento dos táxis.

\subsection{Viagens aleatórias}

Para um período correspondente a duas horas (i.e., $7200 \mathrm{~s}$ ) de simulação, foram gerados trajetos aleatórios para táxis ao longo do mapa inteiro. Um táxi aleatório foi inserido a cada $0,75 \mathrm{~s}^{4}$, totalizando 8.665 veículos com trajetos válidos. Essas viagens aleatórias foram as mesmas para os diferentes intervalos de horários considerados para a extração dos padrões. Como especificado anteriormente, somente os traços dos táxis são efetivamente extraídos.

Os padrões de trajetos (i.e., TAS) identificados pelo T-Pattern foram aqueles que apresentaram entre $2,5 \%$ e $3,5 \%$ de repetição; as demais viagens podem ser consideradas aleatórias, já que não houve nenhuma repetição do mesmo TAS no período analisado. Esses trajetos inseridos com o RandomTrips, do SUMO, servem para simular esse comportamento. O resultado é que cerca de $2 \%$ de todos os veículos na simulação são de fato baseados no padrão identificado pelo T-Pattern.

\subsection{Personalização do tipo de veículo táxi}

O SUMO permite a personalização do tipo de veículo especificado nos trajetos. O veículo táxi foi personalizado com os seguintes parâmetros:

- accel (aceleração): $3 \frac{\mathrm{m}}{\mathrm{s}}$;

- decel (desaceleração): $5 \frac{\mathrm{m}}{\mathrm{s}}$;

- length, width, height (comprimento, largura, altura do veículo): 4, 3m x 1,8m x 1,5m;

- minGap (distância mínima do veículo à frente): $1,5 \mathrm{~m}$;

- speedFactor (coeficiente de "desobediência" do limite de velocidade na via): 1,5 ;

- speedDev (desvio padrão da velocidade média): 0,5 .

Esse tipo foi atribuído tanto aos trajetos gerados a partir dos padrões bem como para as viagens aleatórias geradas para táxis do mapa inteiro. Os veículos do tipo passenger e private, bem como os demais parâmetros do tipo táxi, foram mantidos com

40 parâmetro foi passado para o RandomTrips, do SUMO, para que ele gerasse esses trajetos; no entanto, trajetos impossiveis são removidos, resultando em um número menor de viagens do que o previsto

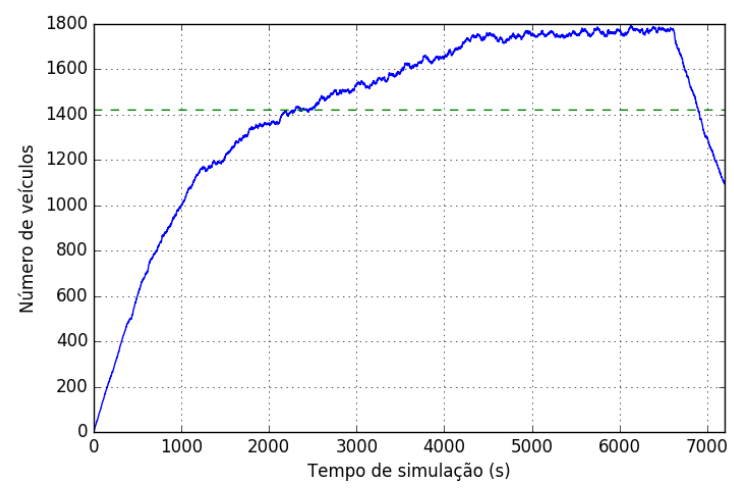

Figura 8: Variação no número de veículos simultâneos ao longo do período de 07:00 às 09:00

os valores padrões ${ }^{5}$.

\subsection{Configuração da simulação}

O SUMO possui diversas opções de configuração ${ }^{6}$, para a simulação dos táxis foram utilizadas as seguintes opções:

- input.net-file: arquivo com a definição do mapa (rede) da simulação;

- input.route-files: arquivo com a definição das rotas dos táxis seguindo os padrões identificados pelo T-Pattern;

- input.additional-files: arquivo com a definição das regiões de interesse identificadas pelo T-Pattern $\mathrm{e}$ a definição das rotas dos táxis aleatórios gerados pelo RandomTrips;

- output.fcd-output: arquivo que armazena os traços da simulação no formato FCD;

- output.fcd-output.geo: opção para salvar os traços com as coordenadas geográficas;

- time.begin: tempo inicial da simulação (em segundos), definido como os;

- time.end: tempo final da simulação (em segundos), definido como 7200 ;

• time.step-length: "passo"da simulação, definido como 1s;

- processing.ignore-route-errors: ignora erros de rotas gerados por acidentes ou erros no roteamento dos táxis.

\section{Resultados}

No total, teve-se 8.665 táxis aleatórios e 645 táxis seguindo os padrões de transição entre ROIs Os veículos foram adicionados gradativamente à simulação e, assim que terminavam seus trajetos, eram removidos pelo SUMO. O gráfico da Figura 8 apresenta a variação no número de veículos simultâneos ao longo do tempo em um dos períodos simulados.

Os veículos aleatórios foram inseridos até o tempo

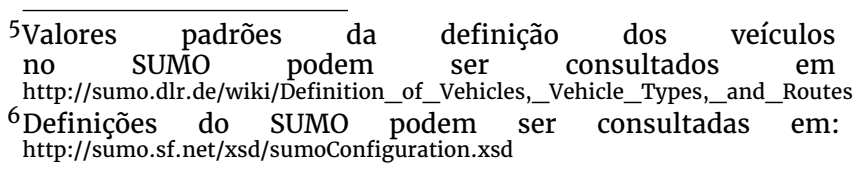




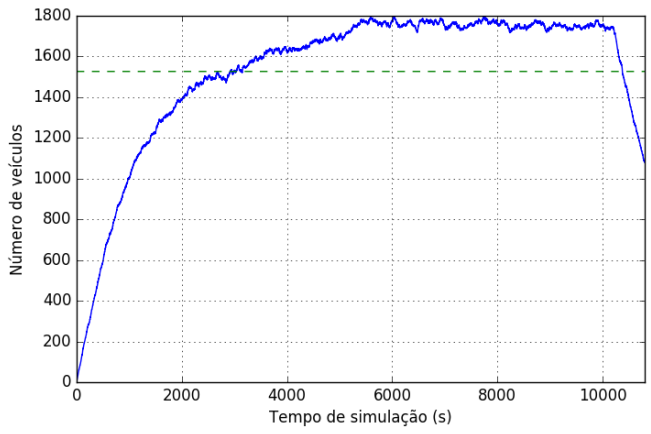

(a) Simulação no período das 11:00 às 14:00

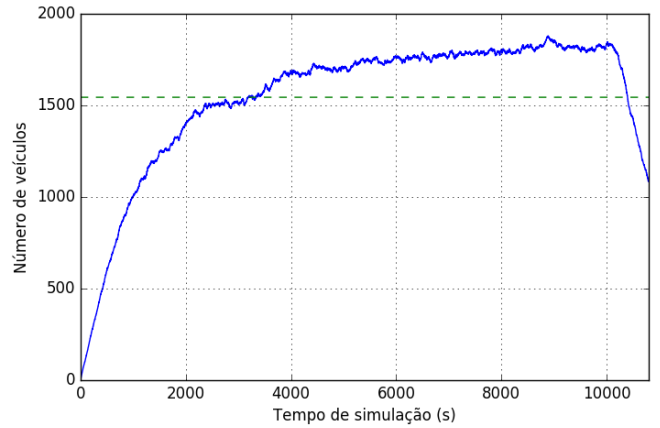

(b) Simulação no período das 17:00 às 19:00

Figura 9: Variação no número de veículos na simulação nos intervalos das 11:00 às 14:00 e 17:00 às 19:00

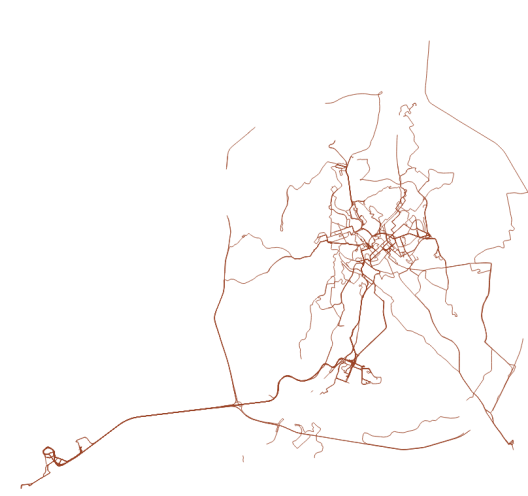

(a) Traços reais de mobilidade no período

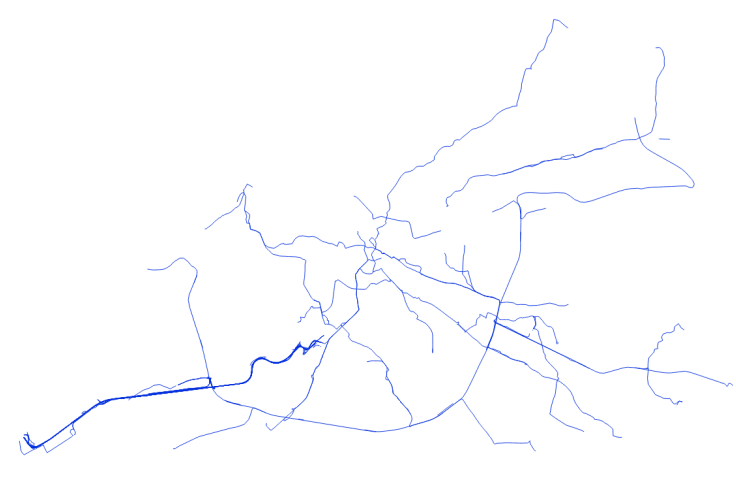

(b) Traços da simulação no período

Figura 10: Comparação das ruas por onde passaram os táxis dos traços reais e da simulação no período das 07:00 às 09:00

de simulação de $6600 \mathrm{~s}$, instante em que é possível ver uma queda brusca do número de veículos ativos (vide Figura 8). Toda vez que um veículo finaliza seus trajetos, ele é removido da simulação pelo SUMO. A média de veículos ativos na simulação no intervalo das 07:00 às 09:00 foi de, aproximadamente, 1420 veículos.

A média de veículos ativos na simulação nos períodos das 11:00 às 14:00 e das 17:00 às 19:00 foram, respectivamente, 1526 e 1544 (vide Figura 9). A queda brusca no número de veículos ativos deu-se pelo fato que muitos táxis simulados percorreram trajetos curtos. Do ponto de vista de coleta de traços e futuras simulações, essa é uma característica desfavorável do SUMO. Ressalta-se que não foi possível encontrar uma maneira de atribuir vários itinerários ao mesmo táxi, ou especificar várias "corridas" para o mesmo ID de táxi. Ou seja, após um táxi (identificado por um ID) terminar um trajeto, o táxi é removido da simulação. Através da matriz de origens e destinos computada a partir dos padrões identificados, gerouse um número determinado de viagens de acordo com a quantidade de repetições dos padrões identificados.

Nas figuras 10, 11 e 12 são apresentadas comparações entre as ruas percorridas pelos táxis reais selecionados e os táxis da simulação no SUMO. É possível perceber que não houve uma repetição muito confiável, com exceção do trecho no canto inferior esquerdo que culmina no aeroporto da cidade de Roma. Isso reflete o fato que há muitas viagens entre locais no centro da cidade e o aeroporto.

As figuras 13, 14 e 15 complementam os resultados anteriores apontando os locais de maior concentrações de táxis. As cores variam de um azul (indicando pouca concentração), passando por tons mais quentes até vermelho (indicando grande concentração). Percebe-se duas principais concentrações nos traços reais na região central da cidade e no aeroporto (canto inferior esquerdo). Os padrões identificados nesta análise estão todos concentrados ao longo do caminho do centro em direção ao aeroporto.

Esses resultados refletem, sobretudo, o método escolhido para a identificação dos padrões. Um padrão é considerado quando há um deslocamento de um táxi pelas mesmas regiões, levando-se o mesmo tempo para transitar de uma região para outra (dentro de uma tolerância de 10 minutos).

Os resultados mostram que esse tipo de análise identifica apenas os principais fluxos de veículos, onde o padrão de movimentação é semelhante no espaço e tempo.

Como a matriz de origens e destinos gerou traços a partir do início e fim dos padrões identificados, muito provavelmente as viagens reais poderiam ter sido inicializadas em outro ponto da cidade, com um perfil de deslocamento não seguindo um padrão bem 


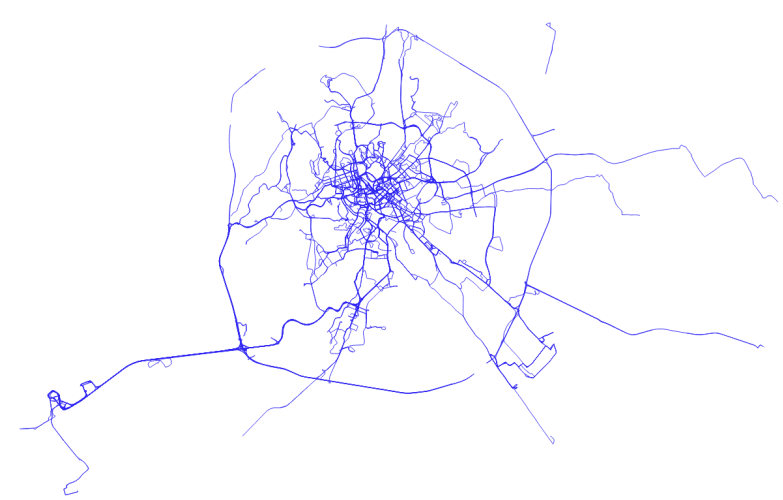

(a) Traços reais de mobilidade

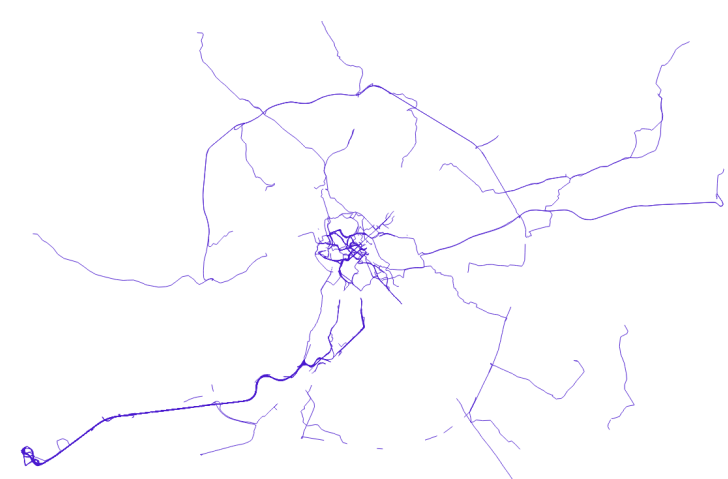

(b) Traços da simulação no período

Figura 11: Comparação das ruas por onde passaram os táxis dos traços reais e da simulação no período das 11:00 às 14:00

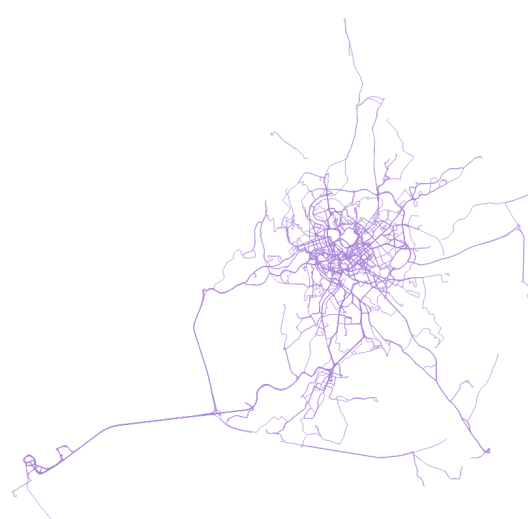

(a) Traços reais de mobilidade no período

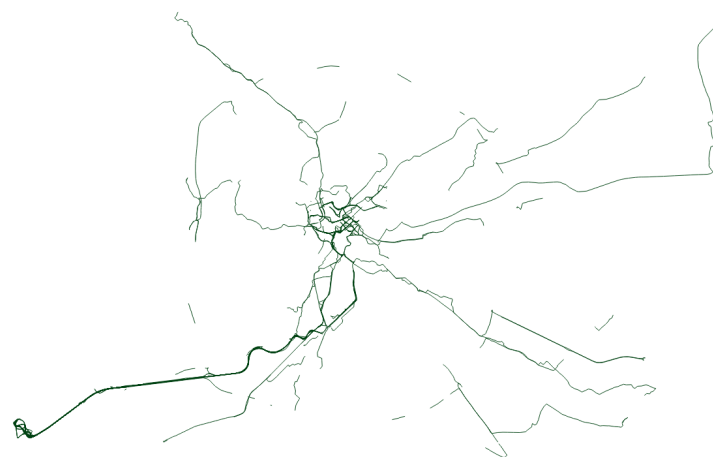

(b) Traços da simulação no período

Figura 12: Comparação das ruas por onde passaram os táxis dos traços reais e da simulação no período das $17: 00$ às 19:00

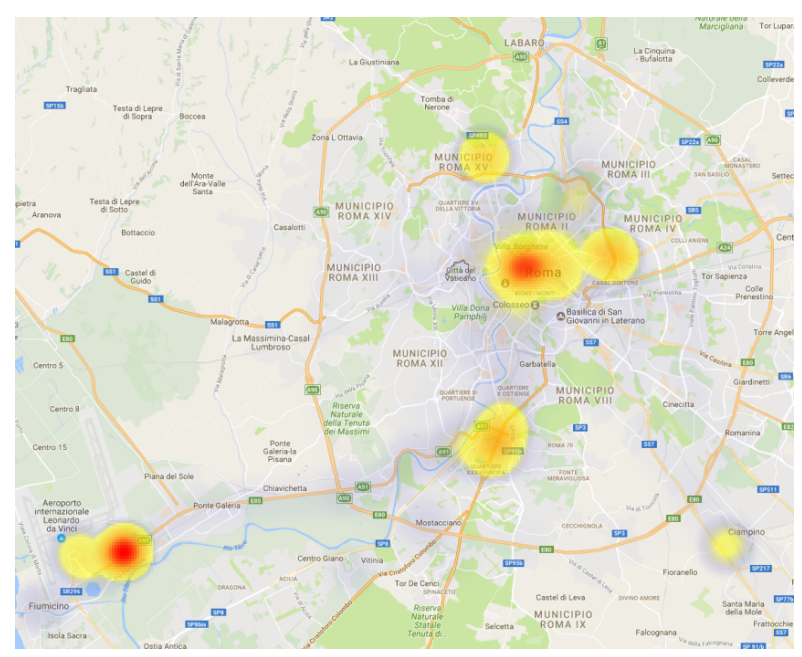

(a) Traços reais de mobilidade no período

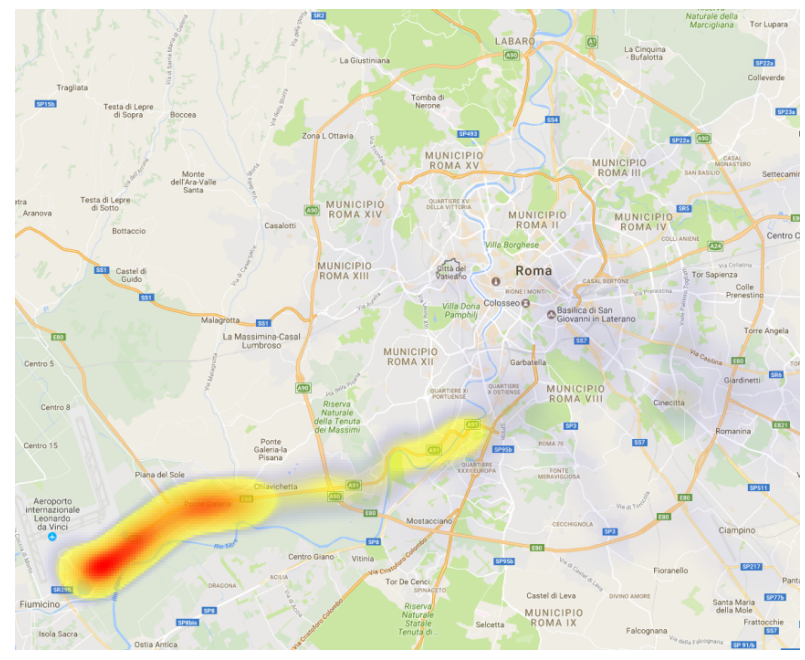

(b) Traços da simulação no período

Figura 13: Comparação do heatmap dos táxis dos traços reais e da simulação no período das 07:00 às 09:00 


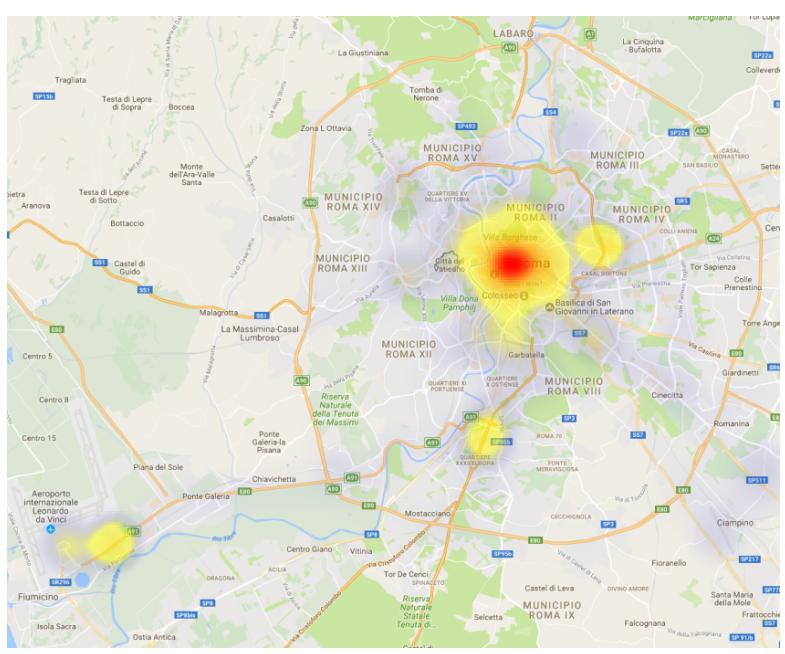

(a) Traços reais de mobilidade

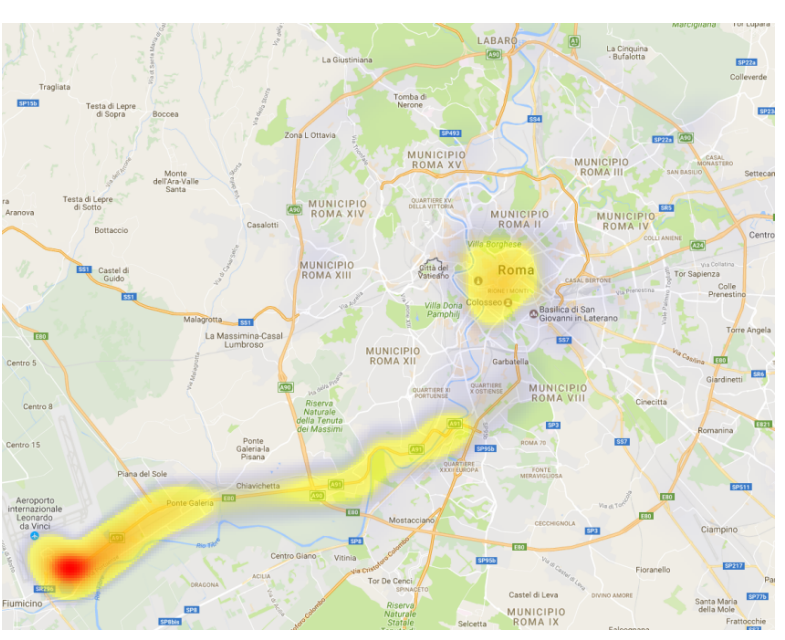

(b) Traços da simulação no período

Figura 14: Comparação do heatmap dos táxis dos traços reais e da simulação no período das 11:00 às 14:00

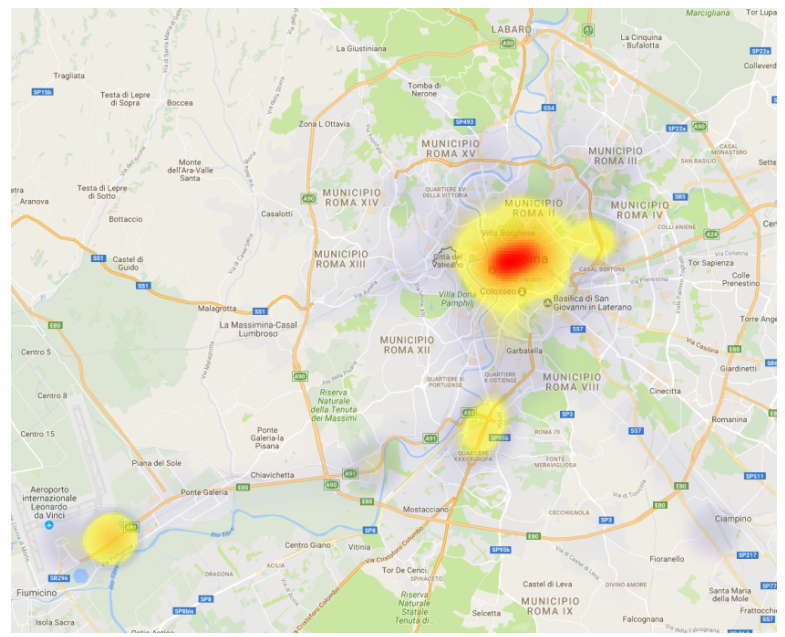

(a) Traços reais de mobilidade no período

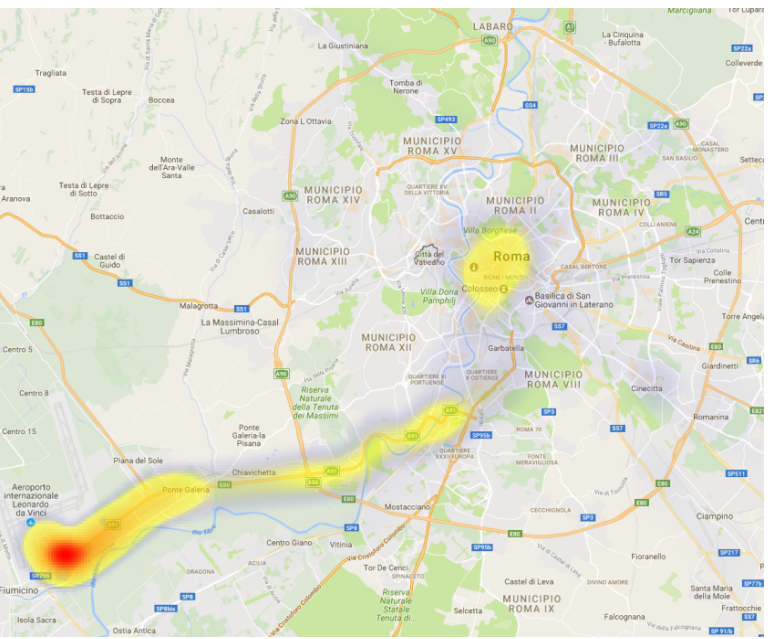

(b) Traços da simulação no período

Figura 15: Comparação do heatmap dos táxis dos traços reais e da simulação no período das 17:00 às 19:00

definido, acentuando-se mais como padrão apenas quando atingisse uma região onde o fluxo de veículos fosse mais regular.

Outro ponto importante a ressaltar é que foram selecionados apenas 10 táxis para analisar os padrões de movimentação. Na simulação foram simulados, respectivamente, 610,1500 e 945 táxis nos três intervalos de horários selecionados (i.e., 07:00 às 09:00, 11:00 às 14:00 e 17:00 às 19:00). Na segunda simulação houve mais veículos devido ao tempo maior de simulação. Nas outras duas, a variação deu-se devido a dois fatores: o gerador de rotas do SUMO removeu algumas rotas inválidas durante $o$ processo de geração; a matriz de origens e destinos apresentou alguns padrões com poucas repetições, requerendo a inserção de algumas viagens adicionais para representá-los. Os gráficos de distribuição dos veículos contemplam também 2.000 dos veículos aleatórios inseridos para interagir com os táxis simulados.

\section{Conclusões}

O modelo de mobilidade proposto conseguiu identificar alguns padrões mais significativos durante o processo de análise. No entanto, nem todos os padrões foram extraídos com sucesso. Uma análise mais aprofundada que apontasse com maior precisão as origens das viagens (i.e., corridas) poderia resultar em trajetos sintéticos mais semelhantes aos táxis reais.

Em síntese, a solução apresentada possibilita uma maneira de gerar traços de táxis em um grande centro urbano com um controle de movimentação microscópico (controlado pelo SUMO) e macroscópico (gerado pela matriz de origens e destinos identificada nos padrões).

Devido à finalidade original do SUMO, ao utilizarse de matrizes de origens e destinos (simulação de trajetos e fluxos) não é possível gerar vários trajetos para os mesmos táxis (i.e., mesmos IDs). Dependendo do simulador de rede, e protocolos, onde os traços gerados forem aplicados, pode-se ter problemas já 
que os identificadores dos veículos ativos alteram com uma frequência significativa (i.e., sai um táxi toda vez que termina um trajeto e entra um novo conforme a distribuição feita pelo SUMO ao longo do período simulado).

\section{Referências}

Bracciale, L., Bonola, M., Loreti, P., Bianchi, G., Amici, R. and Rabuffi, A. (2014). CRAWDAD dataset roma/taxi (v. 2014-07-17). Disponível em http: //crawdad.org/roma/taxi/20140717 (Accessado 16 Setembro 2017).

Camp, T., Boleng, J. and Davies, V. (2002). A survey of mobility models for ad hoc network research, Wireless communications and mobile computing 2(5): 483-502.

Cunha, F. D., Alvarenga, D. A., Viana, A. C., Mini, R. A. and Loureiro, A. A. (2015). Understanding interactions in vehicular networks through taxi mobility, Proceedings of the 12th ACM Symposium on Performance Evaluation of Wireless Ad Hoc, Sensor, \& Ubiquitous Networks, ACM, pp. 17-24.

Giannotti, F., Nanni, M., Pinelli, F. and Pedreschi, D. (2007). Trajectory pattern mining, Proceedings of the 13th ACM SIGKDD international conference on Knowledge discovery and data mining, ACM, pp. 330339.

Göbelbecker, M., Dornhege, C. et al. (2009). Realistic cities in simulated environments-an open street map to robocup rescue converter, Fourth International Workshop on Synthetic Simulation and Robotics to Mitigate Earthquake Disaster (SRMED 2009).

Hess, A., Hummel, K. A., Gansterer, W. N. and Haring, G. (2015). Data-driven human mobility modeling: A survey and engineering guidance for mobile networking, ACM Computing Surveys (CSUR) 48(3): 38 .

Huang, H., Zhu, Y., Li, X., Li, M. and Wu, M.-Y. (2010). Meta: A mobility model of metropolitan taxis extracted from gps traces, Wireless Communications and Networking Conference (WCNC), 2010 IEEE, IEEE, pp. 1-6.

Kotz, D., Henderson, T., Abyzov, I. and Yeo, J. (2009). CRAWDAD dataset dartmouth/campus (v. 2009-0909). Disponível em https: //crawdad . org/dartmouth/ campus/20090909 (Accessado 16 Setembro 2017).

Krajzewicz, D., Erdmann, J., Behrisch, M. and Bieker, L. (2012). Recent development and applications of SUMO - Simulation of Urban MObility, International Journal On Advances in Systems and Measurements 5(3\&4): 128-138.

Madi, S. and Al-Qamzi, H. (2013). A survey on realistic mobility models for vehicular ad hoc networks (vanets), Networking, Sensing and Control (ICNSC), 2013 1oth IEEE International Conference on, IEEE, pp. 333-339.

Neis, P., Zielstra, D. and Zipf, A. (2011). The street network evolution of crowdsourced maps:
Openstreetmap in germany 2007-2011, Future Internet 4(1): 1-21.

Saha, A. K. and Johnson, D. B. (2004). Modeling mobility for vehicular ad-hoc networks, Proceedings of the 1st ACM international workshop on Vehicular ad hoc networks, ACM, pp. 91-92.

Sommer, C., German, R. and Dressler, F. (2011). Bidirectionally Coupled Network and Road Traffic Simulation for Improved IVC Analysis, IEEE Transactions on Mobile Computing 10(1): 3-15.

Varga, A. (1999). Using the omnet++ discrete event simulation system in education, IEEE Transactions on Education 42(4): 11 pp.-.

Wegener, A., Piórkowski, M., Raya, M., Hellbrück, H., Fischer, S. and Hubaux, J.-P. (2008). Traci: an interface for coupling road traffic and network simulators, Proceedings of the 11th communications and networking simulation symposium, ACM, pp. 155163.

Zhang, L., Ahmadi, M., Pan, J. and Chang, L. (2012). Metropolitan-scale taxicab mobility modeling, Global Communications Conference (GLOBECOM), 2012 IEEE, IEEE, pp. 5404-5409. 